\title{
ESTIMASI PARAMETER DISTRIBUSI EKPONENSIAL PADA LOKASI TERBATAS
}

(Estimating Parameter Distribution Exponential At Finite Location)

\author{
MOZART W TALAKUA ${ }^{1}$, JEFRI TIPKA ${ }^{2}$ \\ ${ }^{1}$ Staf Jurusan Matematika, FMIPA,UNPATTI \\ ${ }^{2}$ Calon Staf Jurusan Matematika, FMIPA,UNPATTI \\ Jl. Ir. M. Putuhenam, Kampus Unpatti, Poka-Ambon \\ E Mail: ocat_08@yahoo.com
}

\begin{abstract}
The common method in Estimating Parameter Distribution Exponential at Finite Location is Maximum Likelihood Estimation (MLE).The best estimator is consistent estimator. Because of The Mean Square Error (MSE) can be used in comparing some detectable estimators that it had looking for with Maximum Likelihood Estimation (MLE) so can find the consistent estimator in Estimating Parameter Distribution Exponential At Finite Location.
\end{abstract}

Keywords: Distribution Exponential, Estimator, Finite Location, Parameter.

\section{PENDAHULUAN}

Jika data dikumpulkan melalui sampel random dari suatu populasi, tujuan yang paling utama dari suatu analisis statistik adalah melakukan inferensi atau generalisasi tentang karateristik populasi itu dari infornasi yang terkandung dalam data sampel tersebut. Dapat dilihat bahwa kumpulan data variabel acak yang bebas atau suatu sampel data yang diambil secara acak dari suatu populasi yang mempunyai distribusi. Biasanya dituju pada sifat numerik populasi itu, seperti mean dan variansi distribusi populasi itu. Setiap sifat numerik suatu distribusi populasi dapat dinyatakan dalam bentuk parameter yang tampak dalam fungsi probabilitas populasi itu.

Inferensi atau generalisasi tergantung pada maksud dan tujuan penyelidikan. Dua macam inferensi yang paling penting adalah Estimasi Parameter dan Uji Hipotesis Statistik.

Biasanya parameter populasi dipandang sebagai suatu konstanta yang tidak diketahui harga sebenarnya. Jika berdasarkan data sampel kita ingin menduga atau memperkirakan harga parameter itu dengan kecermatan tertentu, maka inferensinya dinamakan Estimasi Parameter.

Suatu statistik yang digunakan sebagai estimasi suatu parameter dinamakan Estimator Titik parameter itu. Tujuan dari estimasi titik adalah menghasilkan suatu bilangan yang harganya dekat dengan harga parameter yang tidak diketahui misalkan dipunyai sampel acak $X_{1}, X_{2}, \ldots, X_{n}$ dari suatu populasi probabilitas $f(x ; \hat{\theta})$ dan seringkali ditulis estimasi titik $\hat{\theta}$ sebagai estimasi parameter $\theta$. Fungsi probabilitas estimator $\theta$ seringkali dapat diturunkan (dengan menggunakan fungsi Pembangkit Momen atau transformasi variabel) apabila fungsi probabilitas populasinya diketahui.

Hal yang sudah dipelajari secara menyeluruh adalah, bahwa distribusi populasi atau distribusi variabel acaknya mempunyai bentuk matematika yang diketahui. Sebagai contoh, misalkan populasi mempunyai distribusi normal dengan parameter $\mu$ dan $\sigma$, yang tidak diketahui, atau misalkan populasi mempunyai distribusi binomial $b(n, p)$, dimana $p$ tidak diketahui.

Untuk mencari nilai parameter dari $\theta$ (populasi yang mempunyai Distribusi Eksponensial), maka terlebih dahulu dicari Maximum Likelihood Estimation (MLE) dari $\theta$ serta distribusinya baik dalam lokasi/ruang parameter tak terbatas maupun terbatas.

\section{TINJAUAN PUSTAKA}

Memperoleh suatu estimator yang dianggap baik untuk mengestimasi parameter adalah permasalahan yang mendasar dalam suatu populasi.

Dalam pandangan teori keputusan 'pengamatan (data)' yang biasanya dengan distribusi yang tidak diketahui sebelumnya, misal data yang mengandung parameter $\theta \in \Theta$, dengan $\Theta$ diketahui, bersama dengan 'kemungkinan kerugian/keuntungan' akibat pemilihan satu dari sejumlah keputusan yang mungkin merupakan dua unsur utama dalam persoalan umum statistika.

Adapun sampel yang digunakan dalam penelitian disebut sebagai penduga (estimator). Sedangkan fungsi nilai sampel yang digunakan untuk menduga parameter disebut penduga parameter dan angka yang merupakan hasilnya disebut dugaan secara statistik. Suatu penduga $\delta$ dikatakan baik jika memiliki sifat-sifat tidak bias, efisiaen, konsisten.

Keputusan biasanya disebut aksi atau tindakan yang dinotasikan dengan $A$, himpunan keputusan yang mungkin dinotasikan dengan $\mathcal{A}$, dan himpunan variabel random atau ruang sampel dinotasikan dengan $\chi$. Bila fungsi distribusi dari variable random $X_{1}, X_{2}, . ., X_{n}$ bergantung pada $\theta$ yang tidak diketahui, maka persoalan mengestimasi $\theta$ merupakan persoalan estimasi 
titik. $\theta$ diestimasi oleh suatu fungsi dari pengamatan $X_{1}, X_{2}, . ., X_{n}$ yang disebut statistik atau estimation.

Selain itu, estimator-estimator tersebut di atas juga mempunyai sifat-sifat analitik yang nantinya dipakai dalam mengestimasi parameter. Oleh karena itu, penulis mencoba untuk menggambarkan secara ringkas sifat-sifat dari estimator-estimator tersebut di atas dengan bertolak dari definisi-definisi yang ada.

\section{Definisi 1 Fungsi Densitas Probabilitas}

Fungsi $f(x)$ adalah fungsi kepadatan jika $X$ kontinu, dan sering disebut fungsi densitas probabilitas (density probability function)

Fungsi densitas probabilitas dari variabel $X$ yang kontinu adalah $f(x)$, sedemikian hingga:

$$
P(a<X \leq b)=\int_{a}^{b} f(x) d x,
$$

dimana

$$
f(x) \geq 0 \operatorname{dan} \int_{-\infty}^{x} f(x) d x=1
$$

\section{Definisi 2Rataan Fungsi Densitas Probabilitas}

Jika $X$ adalah variabel random kontinu dan $f(x)$ adalah nilai dari fungsi kepadatan pada $x$, maka meannya adalah

$$
E(X)=\int_{-\infty}^{\infty} x \cdot f(x) d x
$$

Selanjutnya, jika $X$ adalah variabel random kontinu dan $f(x)$ adalah nilai dari fungsi kepadatan pada $x$, nilai harapan dari $g(X)$ diberikan oleh

$$
E[g(X)]=\int_{-\infty}^{\infty} g(x) \cdot f(x) d x
$$

\section{Definisi 3 Variansi Fungsi Densitas Probabilitas}

Jika $X$ adalah variabel random kontinu dan $f(x)$ adalah nilai dari fungsi kepadatan pada $X$, variansi dari $X$ adalah

$$
\sigma^{2}=E\left([X-\mu]^{2}\right)=\int_{-\infty}^{\infty}(x-\mu)^{2} f(x) d x .
$$

atau dapat ditulis dalam bentuk lain

$$
\operatorname{Var}(X)=E\left(X^{2}\right)-\mu^{2}
$$

\section{Sifat-sifat Kebaikan dari Suatu Estimator}

Sampel yang digunakan dalam penelitian disebut sebagai penduga (estimator). Sedangkan fungsi nilai sampel yang digunakan untuk menduga parameter disebut penduga parameter dan angka yang merupakan hasilnya disebut dugaan secara statistik. Suatu penduga $\delta$ dikatakan baik jika memiliki sifat-sifat sebagai berikut:

\section{Definisi 4 Tidak Bias}

Suatu penduga $\delta$ dikatakan tidak bias bagi parameternya $\theta$ apabila nilai penduga sama dengan nilai yang diduganya (parameter)

$$
E(\text { penduga })=\text { parameternya }
$$

Jadi, penduga tersebut secara tepat dapat menduga nilai parameternya .
Sebaliknya, suatu penduga dikatakan bias bagi parameternya jika nilai penduga tersebut tidak sama dengan nilai yang diduganya (parameternya), atau dapat ditulis:

$$
[\operatorname{bias}(\delta)]=E(\delta)-\theta
$$

Dengan $E(\delta)$ dinamakan Kuadrat Tengah Galat, dan $|\delta-\theta|$ disebut galat pendugaan.

\section{Definisi 5 Efisien}

Suatu estimator dikatakan efisien bagi parameternya apabila estimator tersebut memiliki variansi yang lebih kecil, dan apabila terdapat lebih dari satu estimator, estimator yang efisien adalah yang memiliki variansi terkecil.

\section{Definisi 6 Konsisten}

Jika $\left\{\delta_{n}\right\}$ merupakan barisan estimator dari parameter $\theta$, estimator ini dikatakan konsisten dari $\theta$ jika untuk setiap $\varepsilon>0$,

$$
\lim _{n \rightarrow \infty} P\left[\left|\delta_{n}-\theta\right|<\varepsilon\right]=1
$$

untuk setiap $\theta \in \Omega$

Suatu estimator dikatakan konsisten apabila memenuhi syarat berikut:

a. Jika ukuran sampel semakin bertambah maka estimator akan mendekati parameternya, jika besarnya sampel menjadi tak berhingga maka estimator konsisten harus dapat memberi suatu dugaan titik yang sempurna terhadap parameternya. Jadi $\delta$ merupakan estimator konsisten jika dan hanya jika:

$$
E(\delta-\theta)^{2} \rightarrow 0 \text { jika } n \rightarrow \infty
$$

b. Jika ukuran sampel bertambah tak berhingga maka distribusi dari estimator akan mengecil.

\section{Definisi 7}

a. Suatu estimator $\delta_{1}$ lebih baik dari $\delta_{2}$ jika $R\left(\theta, \delta_{1}\right) \leq R\left(\theta, \delta_{2}\right)$ untuk semua $\theta$, dan untuk suatu $\theta_{0}, R\left(\theta_{0}, \delta_{1}\right) \leq R\left(\theta_{1}, \delta_{2}\right)$.

b. Estimator $\delta_{1}$ ekivalen dengan $\delta_{2}$ jika $R\left(\theta, \delta_{1}\right)=R\left(\theta, \delta_{2}\right)$

\section{Maximum Likelihood Estimation (MLE)}

Salah satu metode yang terkenal dalam memperoleh salah satu estimator ialah metode kemungkinan maksimum yang didefinisikan sebagai berikut:

\section{Definisi 8}

Misalkan $\left(x_{1}, x_{2}, \ldots, x_{n}\right)$ adalah sampel random iid dari populasi dengan $p d f f\left(x \mid \theta_{1}, \theta_{2}, \ldots, \theta_{n}\right)$ maka Fungsi kemungkinan adalah 


$$
\begin{aligned}
L(\theta \mid x) & =L\left(\theta_{1}, \theta_{2}, \ldots, \theta \mid x_{1}, x_{2}, \ldots, x_{n}\right) \\
& =\prod_{i=1}^{n} f\left(x_{i} \mid \theta_{1}, \theta_{2}, \ldots, \theta\right)
\end{aligned}
$$

\section{Definisi 8}

Estimator $\hat{\theta}=\hat{\theta}\left(x_{1}, x_{2}, \ldots, x_{n}\right)$ disebut $M L E$ dari $\theta$ jika:

$$
L(\hat{\theta} \mid x)=\operatorname{Sup} L\left(\theta \mid x_{1}, x_{2}, \ldots, x_{n}\right), \quad \theta \in \Theta
$$

Jika fungsi kemungkinan terdiferensialkan dalam $\theta$, maka nilai-nilai $\sigma_{1}, \sigma_{2}, \ldots, \sigma_{n}$ diperoleh dengan menyamakan turunan parsial dari fungsi kemungkinan atau logaritmanya dengan nol dan mencari akar-akarnya dan syarat perlu pencapaian maksimum adalah turunan keduanya bernilai dua parameter. Dalam kasus persamaan turunan parsial tidak mempunyai penyelesaian, $M L E$ diperoleh dengan argumentasi.Bila suatu variabel random diketahui distribusi tertentu seringkali diinginkan untuk mengetahui distribusi dari fungsi variabel random atau suatu statistik.

\section{Mean Square Error (MSE)}

Untuk membandingkan suatu estimator dengan estimator lainnya diperlukan ukuran tertentu, salah satu ukuran kualitas dari suatu estimator adalah Mean Square Error (MSE), didefinisikan sebagai berikut:

\section{Definisi 9}

MSE dari estimator $\delta=\delta(x)$ dan parameter $\theta$ adalah fungsi yang didefinisikan oleh:

$$
\operatorname{MSE}(\delta-\theta)=E(\delta-\theta)^{2}
$$

dengan : $[\operatorname{bias}(\delta)]=E(\delta)-\theta$

karena

Maka

$$
\operatorname{Var}(\delta-\theta)=E(\delta-\theta)^{2}-[E(\delta-\theta)]^{2}
$$

$$
\operatorname{MSE}(\delta-\theta)=\operatorname{Var}(\delta)+[\operatorname{bias}(\delta)]^{2}
$$

\section{Teorema 1}

Jika $\delta$ adalah estimator dari parameter $\theta$, maka:

$$
\operatorname{MSE}(\delta)=\operatorname{Var}(\delta)+[\operatorname{bias}(\delta)]^{2}
$$

Bukti :

$$
\begin{aligned}
\operatorname{MSE}(\delta) & =E(\delta-\theta)^{2} \\
& =E[\delta-E(\delta)+E(\delta)-\theta]^{2} \\
& =E[\delta-E(\delta)]^{2}+E[E(\delta)-\theta]^{2}
\end{aligned}
$$

$$
\begin{aligned}
= & E\left[\delta^{2}-2 \delta E(\delta)+(E(\delta))^{2}\right]+E\left[[E(\delta)]^{2}-2 E(\delta) \theta+\theta^{2}\right] \\
= & {\left[E\left[(\delta)^{2}\right]-2 E[(\delta) E(\delta)]+E[E(\delta)]^{2}\right] } \\
& +\left[[E(\delta)]^{2}-2 E[E(\delta)(\theta)]+E\left[\theta^{2}\right]\right] \\
= & {\left[E(\delta)^{2}-2[E(\delta)(E(\delta))]+[E(\delta)]^{2}\right] } \\
& +\left[[E(\delta)]^{2}-2[E(\delta)(\theta)]+\left[\theta^{2}\right]\right] \\
= & {\left[E(\delta)^{2}-2[E(\delta)(E(\delta))]+[E(\delta)]^{2}\right]+[\operatorname{Bias}(\delta)]^{2} } \\
= & {\left[E(\delta)^{2}-2[E(\delta)]^{2}+[E(\delta)]^{2}\right]+[\operatorname{Bias}(\delta)]^{2} } \\
= & {\left[E(\delta)^{2}-[E(\delta)]^{2}\right]+[\operatorname{Bias}(\delta)]^{2} } \\
= & \operatorname{Var}(\delta)+[\operatorname{Bias}(\delta)]^{2}
\end{aligned}
$$

Diketahui bahwa:

$$
[\operatorname{bias}(\delta)]=E(\delta)-\theta
$$

maka dapat ditulis:

$$
E(\delta)=\theta
$$

sehingga,

$$
\operatorname{MSE}(\delta-\theta)=\operatorname{Var}(\delta)+\left[E(\theta)^{2}-2[E(\theta)(E(\theta))]+[E(\theta)]^{2}\right]
$$
atau

$$
\operatorname{MSE}(\delta)=\operatorname{Var}(\delta)+[\operatorname{bias}(\delta)]^{2}
$$

Jadi MSE merupakan ukuran kualitas yang mempunyai dua komponen varian sebagai pengukur varibilitas dan bias sebagai pengukur keakuratan dari estimator, dengan kata lain bila suatu estimator tak bias maka MSE-nya sama dengan variansinya.

\section{Definisi 10}

Barisan estimator $\left\{\theta_{n}\right\}$ dikatakan tak bias secara asimtotik untuk $\theta$, jika:

$$
\lim _{n \rightarrow \infty} \operatorname{bias}\left(\delta_{\mathrm{n}}\right)=0 \text {, untuk semua } \theta
$$

\section{Teorema 2}

Barisan estimator $\left\{\theta_{n}\right\}$ untuk $\theta$, dikatakan konsisten dalam kuadrat rata-rata jika dan hanya jika:

1. $\operatorname{Var}\left(\delta_{n}\right) \rightarrow 0, \quad n \rightarrow \infty$

2. $\delta_{\mathrm{n}}$ tak bias secara asimtotik

Bukti:

$$
\text { Karena } \begin{aligned}
E\left(\delta_{n}-\theta^{2}\right) & =\operatorname{Var}\left(\delta_{n}-\theta^{2}\right)+E\left(\delta_{n}-\theta^{2}\right) \\
& =\operatorname{Var}\left(\delta_{n}\right)+\left[\operatorname{bias}\left(\delta_{n}\right)\right]^{2}
\end{aligned}
$$

yang akan menuju 0 jika dan hanya jika kedua sukunya menuju 0

\section{Definisi 11 Metode Momen}

Jika $X_{1}, X_{2}, . ., X_{n}$ adalah suatu sampel random dari $f\left(x ; \theta_{1}, \theta_{2}, \ldots, \theta_{n}\right)$, maka sampel momen ke-k diberikan oleh :

$$
M_{J}=\frac{\sum_{i=1}^{n} x_{i}^{2}}{n} \quad J=1,2, \ldots, k
$$

Dengan momen atau rata-rata yang ditulis $\mu_{1}^{\prime}=\mu$ 


\section{HASIL DAN PEMBAHASAN}

\section{Estimator Parameter Distribusi Eksponensial Pada Lokasi Tak Terbatas}

Misalkan $X_{1}, X_{2}, \ldots, X_{n}$ adalah Variabel Random iid masing-masing berdistribusi eksponensial dengan fungsi kepadatannya:

Maka

$$
f(x \mid \theta)=\frac{1}{\theta} e^{-\frac{x}{\theta}}
$$

$$
\begin{aligned}
& E(X)=\theta \\
& \operatorname{Var}(X)=\theta^{2}
\end{aligned}
$$

dan fungsi kemungkinan adalah :

$$
L(\theta \mid x)=\frac{1}{\theta^{n}} \exp -\left\{\sum_{i=1}^{n}\left(\frac{x_{i}}{\theta}\right)\right\}
$$

dengan $X_{(1)}=\operatorname{Min}\left(X_{1}, X_{2}, \ldots, X_{n}\right)$

untuk setiap $\theta$ tetap, karena $L(\theta \mid x)$ merupakan perkalian antara suatu fungsi yang naik dalam $\theta$ dengan indikator yang nilainya 1 jika $X_{(1)} \in \theta$ dan 0 untuk lainnya. Sehingga $L(\theta \mid x)$ mencapai maksimum pada:

$$
\hat{\theta}=X_{(1)}=\operatorname{Min}\left(X_{1}, X_{2}, \ldots, X_{n}\right)
$$

Selanjutnya diperoleh:

$$
\begin{aligned}
\frac{\partial}{\partial \theta} \log [L(\theta \mid x)] & =\frac{\partial}{\partial \theta} \log \left[\frac{1}{\theta^{n}} \exp -\left\{\sum_{i=1}^{n}\left(\frac{x_{i}}{\theta}\right)\right\}\right] \\
& =\frac{\partial}{\partial \theta}\left[\log \frac{1}{\theta^{n}}+\log e^{\left.-\sum_{i=1}^{n}\left(\frac{x_{i}}{\theta}\right)\right]}\right. \\
& =\frac{\partial}{\partial \theta}\left[\log \theta^{-n}-\sum_{i=1}^{n}\left(\frac{x_{i}}{\theta}\right)\right] \\
& =\frac{\partial}{\partial \theta}\left[-n \log \theta-\frac{1}{\theta} \sum_{i=1}^{n} x_{i}\right] \\
& =-n \frac{1}{\theta}+\frac{1}{\theta^{2}} \sum_{i=1}^{n} x_{i}
\end{aligned}
$$

Dengan menyamakan persamman di atas sama dengan nol maka diperoleh $M L E$ untuk $\theta$ adalah:

$$
\begin{aligned}
& -n \frac{1}{\theta}+\frac{1}{\theta^{2}} \sum_{i=1}^{n} x_{i}=0 \\
& -n \frac{1}{\theta}=-\frac{1}{\theta^{2}} \sum_{i=1}^{n} x_{i} \\
& \frac{n}{\theta}=\frac{1}{\theta^{2}} \sum_{i=1}^{n} x_{i} \\
& \text { Maka } \\
& \theta=\frac{\sum_{i=1}^{n} x_{i}}{n} \\
& \text { atau } \\
& \hat{\theta}=\frac{\sum_{i=1}^{n} x_{i}}{n}=\bar{X}
\end{aligned}
$$

$$
=\frac{S}{n} \text { dengan } S=\sum_{i=1}^{n} x_{i}
$$

Jelas $\hat{\theta}$ memberikan nilai maksimum untuk $L(\theta \mid x)$ sebab:

$$
\begin{aligned}
\frac{\partial}{\partial \theta} \log [L(\theta \mid x)] & =\frac{\partial}{\partial \theta}\left[-n \frac{1}{\theta}+\frac{1}{\theta^{2}} \sum_{i=1}^{n} x_{i}\right] \\
& =\frac{\partial}{\partial \theta}\left[-n \theta^{-1}+\theta^{-2} \sum_{i=1}^{n} x_{i}\right] \\
& =n \theta^{-2}-2 \theta^{-3} \sum_{i=1}^{n} x_{i} \\
& =\frac{n}{\theta^{-2}}-\frac{2}{\theta^{-3}} \sum_{i=1}^{n} x_{i}<0
\end{aligned}
$$

jika dan hanya jika $\theta<2 \hat{\theta}$

dan $L(\theta \mid x) \rightarrow 0$ jika $\theta \rightarrow 0$ atau $\theta \rightarrow \infty$

untuk $\hat{\theta}=X_{(1)}=\operatorname{Min}\left(X_{1}, X_{2}, \ldots, X_{n}\right)$

Akibatnya

$$
\begin{aligned}
P\left[\operatorname{Min}\left(X_{1}, X_{2}, \ldots, X_{n}\right) \leq x\right] & =1-P\left[\operatorname{Min}\left(X_{1}, X_{2}, \ldots, X_{n}\right)>x\right] \\
& =1-P\left[X_{1}>x\right] \ldots P\left[X_{1}>x\right] \\
& =1-\left(P\left[X_{1}>x\right]\right)^{2} \\
& =1-\left(1-P\left[X_{1} \leq x\right]\right) \\
& =1-e^{-\frac{x}{\theta}}
\end{aligned}
$$

Sehingga fungsi kepadatan dari $X_{(1)}$ adalah:

$$
f_{X_{(1)}}(t)=\frac{n}{\theta} e^{\frac{-t}{\theta}} \quad \theta>0
$$

dengan $E\left(X_{(1)}\right)=\frac{\theta}{n} \operatorname{Var}\left(X_{(1)}\right)=\left(\frac{\theta}{n}\right)^{2}$

\section{Teorema 3}

Bila $X_{1}, X_{2}, . ., X_{n}$ adalah Variabel Random iid berdistribusi eksponensial $\exp (\theta)$, maka:

$$
\frac{2 n}{\theta}(\hat{\theta}-\theta) \sim \chi_{(2)}^{2}
$$

Bukti

Dari persamaan diperoleh bahwa $X_{\mathrm{i}} \sim \exp \left(\frac{\theta}{n}\right)$, maka menurut sifat parameter lokasi $X_{\mathrm{i}}-\theta \sim \exp \left(\frac{\theta}{n}\right)$, sehingga

$$
\begin{aligned}
& \psi_{X_{(11)}-\theta}=\left(1-\frac{\theta}{n}\right)^{-1} \\
& \psi_{\frac{2 n}{\theta} X_{(11)}-\theta}=(1-2 t)^{-1}
\end{aligned}
$$

yang merupakan fungsi pembangkit momen dari distribusi Khi-kuadrat dengan derajat kebebasan 2. 
Jadi terbukti bahwa $\frac{2 n}{\theta}(\hat{\theta}-\theta)=\frac{2 n}{\theta}\left(X_{i}-\theta\right) \sim \chi_{(2)}^{2}$

Dari persamaan diperoleh:

$$
\begin{aligned}
E\left(\frac{S}{n}\right) & =\frac{\theta}{n}(n-1) \\
\operatorname{Var}\left(\frac{S}{n}\right) & =\frac{\theta^{2}}{n^{2}}(n-1) \\
E\left(\frac{S}{n}\right)^{2} & =\operatorname{Var}\left(\frac{S}{n}\right)+\left[E\left(\frac{S}{n}\right)\right]^{2} \\
& =\theta^{2}(n-1)
\end{aligned}
$$

$\widehat{\theta}$ merupakan estimator bias, maka diperoleh estimator baru untuk $\theta$, misalnya $\delta_{1}=X_{(1)}-\frac{1}{n^{2}} \sum_{i=1}^{n}\left[X_{i}-X_{(1)}\right]$ yang juga bias tapi bila prosedur dilakukan untuk setiap pengambilan sampel $n,\left\{\delta_{1 n}\right\}$ secara asimtotik tak bias karena $\lim _{n \rightarrow \infty} \operatorname{bias}\left(\delta_{1 n}\right)=0$, sedangkan estimator tak bias untuk $\theta$ adalah:

$$
\begin{aligned}
& U_{1}=-\frac{1}{(n-1)} \sum_{i=1}^{n}\left[X_{i}-X_{(1)}\right] \\
& U_{2}=-\frac{1}{(n)} \sum_{i=1}^{n}\left[X_{i}-X_{(1)}\right]
\end{aligned}
$$

\section{Estimator Parameter Distribusi Eksponensial Pada Lokasi Terbatas}

Sekarang diandaikan dalam pdf parameter lokasi $\theta$ terbatas ke atas oleh $c, \theta \leq c$, dengan $c$ suatu konstanta. Akan tetapi dicari $M L E$ dari $\theta$.

Misalkan $X_{1}, X_{2}, . ., X_{n}$ adalah variabel random iid dari $\exp (\theta)$, dengan $-\infty<\theta \leq c$, maka:

$f(x \mid \theta)=\frac{1}{\theta} e^{-\frac{x}{\theta}}$

dan fungsi kemingkinannya adalah

$$
\begin{aligned}
L(\theta \mid x) & =\frac{1}{\theta^{n}} \exp -\left\{\frac{x_{i}}{\theta}\right\} \prod_{i=1}^{n} \\
& =\frac{1}{\theta^{n}} \exp -\left\{\sum_{i=1}^{n} \frac{x_{i}}{\theta}\right\}
\end{aligned}
$$

Jika diketahui, dan diambil sampel maka kita tidak dapat mengamati $x_{i}$ yang lebih kecil dari $\theta$ karena $L(\theta \mid x)$ adalah perkalian satu fungsi dari $\theta$ naik dengan fungsi indikator yang bernilai 1 untuk $x_{i} \in(\theta, \infty)$ dan 0 untuk lainnya, dan diketahui bahwa $-\infty<\theta<\infty, \hat{\theta}=X_{(1)}$. Tetapi untuk $-\infty<\theta \leq c$, jika $X_{(1)}>c$ maka nilai ini jelas di luar parameter, sehingga untuk $X_{(1)}>C$,
$L(\theta \mid x)$ mencapai maksimum pada $\hat{\theta}=c$, karena itu untuk $-\infty<\theta \leq c$, maka MLE untuk $\hat{\theta}$ adalah :

$\hat{\theta}=\left\{\begin{array}{cc}X_{(1)} & , \text { Jika } X_{(1)} \leq c \\ c & \text {, Jika } X_{(1)}>c\end{array}\right.$

Untuk mendapatkan MLE dari $\theta$ diperoleh dengan cara menyamakan $\frac{\partial}{\partial \theta} \log [L(\theta \mid x)]$ dengan 0 , sehingga didapatkan:

$\hat{\theta}=\frac{1}{n} \sum_{i=1}^{n} x_{i}$

$$
=\left\{\begin{array}{c}
\frac{1}{n} \sum_{i=1}^{n}\left[X_{i}-X_{(1)}\right], \text { Jika } X_{(1)} \leq \mathrm{c} \\
\frac{1}{n} \sum_{i=1}^{n}\left[X_{i}-c\right], \text { Jika } X_{(1)}>\mathrm{c}
\end{array}\right.
$$

Sekarang dengan mengadopsi estimator

$$
\delta_{1}=X_{(1)} \frac{1}{n^{2}} \sum_{i=1}^{n}\left[X_{i}-X_{(1)}\right]
$$

Dalam ruang parameter tak terbatas, dapat dibentuk estimator untuk $\theta$ dalam ruang parameter terbatas (misalkan $\delta_{2}$ ) sebagai berikut:

$$
\delta_{2}=\left\{\begin{array}{cc}
\delta_{1}, & , \text { Jika } X_{(1)} \leq \mathrm{c} \\
c-\frac{1}{n^{2}} \sum_{i=1}^{n}\left[X_{i}-c\right], & \text { Jika } X_{(1)}>\text { c }
\end{array}\right.
$$

Dan para estimator tersebut sekarang akan dibandingkan terhadap kriteria Mean Square Error (MSE), dengan kata lain dicari risiko masing-masing estimator terhadap fungsi kuadratis, dengan memanfaatkan idenpedensi dari $X_{(1)}$ dan $S$

Terlebih dahulu dibanding $\hat{\theta}$ dengan $\delta_{1}$ yang keduanya merupakan bias dalam ruang parameter tak terbatas. Dengan kriteria MSE diperoleh:

$$
\begin{aligned}
\operatorname{MSE}(\hat{\theta})-\operatorname{MSE}\left(\delta_{1}\right) & =E\left[\left(X_{(1)}-\theta\right)^{2}-\left(X_{(1)}-\frac{S}{n^{2}}-\theta\right)^{2}\right] \\
& =\frac{\theta^{2}}{n^{2}}(n-1)\left(\frac{2-n}{n}\right) \\
& =\frac{\theta^{2}}{n^{3}}\left(n-2+n^{2}\right)
\end{aligned}
$$

Dari persamaan (1) dapat menunjukan bahwa $\operatorname{MSE}\left(\delta_{1}\right)<\operatorname{MSE}(\hat{\theta})$ sehingga dapat dinyatakan bahwa $\delta_{1}$ lebih baik daripada $\hat{\theta}$.

Selanjutnya perbandingan $\delta_{1}$ dengan $\delta_{2}$ adalah sebagai berikut:

$\operatorname{MSE}\left(\delta_{1}\right)-\operatorname{MSE}\left(\delta_{2}\right)=E\left[\left(X_{(1)}-\frac{S}{n^{2}}-\theta\right)^{2}\right]-E\left[\left(c-\frac{1}{n^{2}} \sum_{i=1}^{n}\left[X_{i}-c\right]-\theta\right)^{2}\right]$ 


$$
=\frac{(n+1)}{n} E\left[\left(X_{(1)}-c\right)-\frac{(n-1)}{n}\left(X_{(1)}-c\right)-\frac{2 S}{n^{2}}(2 c-2 \theta)\right]
$$

Karena $X_{(1)}$ dan $S$ adalah independen, dan secara kondisional $X_{(1)}>c$, maka $X_{(1)}-c \sim \exp (\theta)$, sehingga $E\left(X_{(1)}-c\right)^{2}=\frac{\theta^{2}}{n^{2}}$, maka diperoleh:

$$
\begin{aligned}
\operatorname{MSE}\left(\delta_{1}\right)-\operatorname{MSE}\left(\delta_{2}\right) & =\frac{n+1}{n}\left[\frac{\theta^{2}}{n^{2}}-\frac{(n-1)}{n} \frac{\theta^{2}}{n^{2}}-\frac{2}{n}(2 c-2 \theta) E\left(\frac{S}{n}\right)\right] \\
& =\frac{4 \theta(n+1)}{n^{4}}\left[n c-\theta n-\frac{\theta}{4}\right]
\end{aligned}
$$

Hasil di atas menunjukan bahwa $\operatorname{MSE}\left(\delta_{1}\right)<\operatorname{MSE}\left(\delta_{2}\right)$ sehingga dapat disusun teorema berikut:

Maka perbandingan antara $\delta_{3}$ dan $\delta_{4}$ menghasilkan:

$$
\begin{aligned}
\operatorname{MSE}\left(\delta_{3}\right)-\operatorname{MSE}\left(\delta_{4}\right)= & E\left[\left(\frac{S}{n^{2}}-\theta\right)^{2}\right]- \\
& E\left[\left(c-\frac{1}{n^{2}} \sum_{i=1}^{n}\left[X_{i}-c\right]-\theta\right)^{2}\right] \\
= & -E\left[\frac{0}{n^{2}}\right]
\end{aligned}
$$$$
=0
$$

Karena $\operatorname{MSE}\left(\delta_{3}\right)=\operatorname{MSE}\left(\frac{S}{n}\right)=\operatorname{Var}\left(\frac{S}{n}\right)+\left[\operatorname{bias}\left(\frac{S}{n}\right)\right]^{2}$

$$
\begin{aligned}
& =\frac{(n-1)}{n^{2}} \theta^{2}+\frac{\theta^{2}}{n^{2}} \\
& =\frac{\theta^{2}}{n^{2}}((n-1)+1) \\
& =\frac{\theta^{2}}{n^{2}}(n) \\
& =\frac{\theta^{2}}{n}
\end{aligned}
$$

Maka $\operatorname{MSE}\left(\delta_{3}\right)=\frac{\theta^{2}}{n}$

\section{Lema 1}

Fungsi kerugian kuadratis $L(\theta \mid \delta)=(\delta-\theta)^{2}$ adalalah konveks tegas dalam $\delta$.

Bukti

Diberikan $\alpha(0<\alpha<1)$ dan $L(\theta \mid \delta)$

1). $L\left(\theta, \alpha\left(\delta_{1}\right)+\left(\delta_{2}\right)\right)=\left[\left(\alpha \delta_{1}+(1-\alpha) \delta_{2}\right)-\theta\right]^{2}$ $=\left(\alpha \delta_{1}+(1-\alpha) \delta_{2}\right)^{2}-2 \theta\left(\alpha \delta_{1}+(1-\alpha) \delta_{2}\right)-\theta^{2}$

2). $\alpha\left(L\left(\theta, \delta_{1}+(1-\alpha) L\left(\theta, \delta_{2}\right)\right)\right)=\alpha\left(\delta_{1}-\theta\right)^{2}+(1-\alpha)\left(\delta_{2}-\theta\right)^{2}$$$
=\alpha \delta_{1}^{2}+(1-\alpha) \delta_{2}{ }^{2}-2 \alpha \theta \delta_{1}+2(1-\alpha) \theta \delta_{2}{ }^{2}+\delta^{2}
$$

$$
\operatorname{MSE}\left(\delta_{5 n}\right)=\frac{2 n-1}{2 n^{2}} \theta^{2}
$$

$$
\begin{aligned}
& L\left(\theta, \alpha\left(\delta_{1}\right)+\left(\delta_{2}\right)\right)-\alpha\left(L\left(\theta, \delta_{1}+(1-\alpha) L\left(\theta, \delta_{2}\right)\right)\right) \\
& =\left(\alpha^{2}-\alpha\right)\left(\delta_{1}{ }^{2}+2 \delta_{1} \delta_{2}+\delta_{2}{ }^{2}\right)<0 \text { karena }\left(\alpha^{2}-\alpha\right)<0
\end{aligned}
$$

Terbukti,

$$
L\left(\theta, \alpha\left(\delta_{1}\right)+\left(\delta_{2}\right)\right)<\alpha\left(L\left(\theta, \delta_{1}+(1-\alpha) L\left(\theta, \delta_{2}\right)\right)\right)
$$

yang berarti $L(\theta \mid \delta)$ adalalah konveks tegas.

Karena $\operatorname{MSE}\left(\delta_{4}\right)=\frac{\theta^{2}}{n}$

Maka $\operatorname{MSE}\left(\delta_{5}\right)=\frac{\theta^{2}}{n}-\frac{\theta^{2}}{2 n^{2}}=\frac{2 n-1}{2 n^{2}} \theta^{2}$

$$
\begin{aligned}
\operatorname{MSE}\left(\delta_{6}\right) & =\frac{\theta^{2}}{n}-\frac{\theta^{2}}{n(n+1)} \\
& =\frac{\theta^{2}}{(n+1)}
\end{aligned}
$$

dapat dinyatakan:

$\operatorname{MSE}\left(\delta_{6}\right)<\operatorname{MSE}\left(\delta_{5}\right)<\operatorname{MSE}\left(\delta_{4}\right)=\operatorname{MSE}\left(\delta_{3}\right)$

Semuanya menuju nol apabila $n$ menuju $\infty$, dengan kata lain estimator yang konsisten dalam kuadrat rata-rata.

\section{KESIMPULAN DAN SARAN}

\section{Kesimpulan}

Berdasarkan hasil pembahasan dari bab-bab sebelumnya dapat disimpulkan bahwa

1. Tujuan dari estimasi titik adalah menghasilkan suatu bilangan yang harganya dekat dengan parameter yang tidak diketahui, Estimator parameter pada lokasi terbatas bergantung pada nilai $n$ sampel dan $\hat{\theta}$ merupakan estimator bias.

2. Mean dan Variansi jika parameter berada pada selang takterbatas berturut-turut adalah $E(X)=\frac{\theta}{n}$ dan $\operatorname{Var}(X)=\left(\frac{\theta}{n}\right)^{2}$

3. Dengan menggunakan metode Mean Square Error (MSE) diperoleh beberapa estimator, yang bila prosedur estimasi serupa untuk setiap pengambilan sampel $n$ terhadap estimator-estimator tersebut. Semuanya menuju nol apabila $n$ menuju $\infty$, dengan kata lain estimator yang konsisten dalam kuadrat rata-rata. Dapat ditunjukan sebagai berikut :

$$
\operatorname{MSE}\left(\delta_{1 n}\right)=\frac{\theta^{2}}{n^{3}}\left(n-2+n^{2}\right)
$$

$$
\operatorname{MSE}\left(\delta_{3 n}\right)=\operatorname{MSE}\left(\delta_{4 n}\right)=\frac{\theta^{2}}{n}
$$

$$
\text { MS }
$$

dengan

$$
\operatorname{MSE}\left(\delta_{6}\right)<\operatorname{MSE}\left(\delta_{5}\right)<\operatorname{MSE}\left(\delta_{4}\right)=\operatorname{MSE}\left(\delta_{3}\right)
$$




\section{DAFTAR PUSTAKA}

Andi, H. N. dan Abdurrauf, R, (1994), Teori Statistika Untuk Ilmu-Ilmu Kuantitatif, Penea Karya AksaraJakartarbit Bhata

Bain, L. J, (1992), Introduction To Probability And Mathematical Statistics, PWS-KENT Publishing Company.

Dudewicz, E. J. dan Mishra, S. N, (1998), Statistika Matematika Modern, ITB Bandung.

Roussas, G. G, (1973), A First Course in Mathematical Statistics, Addison-Wesley Publishing Company, Massachusetts.

Walpole, R. E. dan Myers, R. H, (1995), Ilmu Peluang dan Statistik Untuk Insinyur dan Ilmuan, ITB Bandung. 